\title{
Taking the Customer into Account in Collaborative Design
}

\author{
Maria-Jesus Agost ${ }^{1}$, Margarita Vergara ${ }^{1}$ \\ ${ }^{1}$ Mechanical Engineering and Construction Department, Universitat Jaume I, \\ Castellón, Spain \\ \{magost, vergara\}@emc.uji.es
}

\begin{abstract}
This article describes the improvement of a model of collaborative design for the ceramic industry. A new stakeholder playing a crucial role is now included in the design process, i.e. the customer. Specifically, we present a pilot validation study for the framework that aims to analyse how the environment, experiences and reference criteria of different types of the customers (commercial dealers, final users, architects and interior designers, etc.) can affect their preferences. Information about these customer preferences could be very useful for designers during the early stages of product development. A multidisciplinary approach to the problem can introduce substantial improvements in defining a truly collaborative design chain.
\end{abstract}

Keywords: Collaborative Design, Customer, Subjective Impressions in Design.

\section{Introduction}

New requirements in the management of new product development favour cooperation between the different players in the design system and, as a result, design management has evolved towards enterprise networks and collaborative environments [1]. Yet, although collaborations between manufacturers and suppliers are becoming increasingly more usual, it is still far from common for the customer to be considered as a fundamental participant in the collaborative design chain. The different types of customers (those that 'filter' the product throughout its life cycle) are stakeholders in the process and their preferences should be taken into account from the very earliest design stages. Therefore to include the customer in the product development is another step forward in collaborative design.

This article describes a model of collaborative design for the ceramic industry. It is the result of merging the interests of two research lines related to the design and development of new products, although they are dealt from complementary perspectives, namely improving collaborative processes and taking into account the customers' impressions on the products. Previous work in this area considers these two types of methodologies independently. We believe that a multidisciplinary approach can introduce substantial improvements into the new product design. By incorporating the customer as a new key element we can make advances towards the definition of a truly collaborative design chain. This work is based on a model that 
was developed previously which focused on the management of the relationships among the different participants in the ceramic design chain $[2,3,4]$. The aim of our work here is to enrich the model by taking into account the subjective impressions of different types of customers during the design process. Such observations would be a key factor to design more innovative products that meet the customer expectations better in today's changing and highly competitive markets.

\section{The conceptual framework}

To enrich the previous model with the customer collaboration, a new conceptual framework was developed [5] which establishes the relationships between the subjective impressions elicited in human-product interaction and the designer's work. The main purpose of this framework is to serve as a base for developing a practical tool that can be used by designers to take into account the subjective impressions of different types of customers. The work in this paper is to further develop the framework and make the pilot study on it. Fig. 1 shows the framework and the focus of the work presented in this paper.

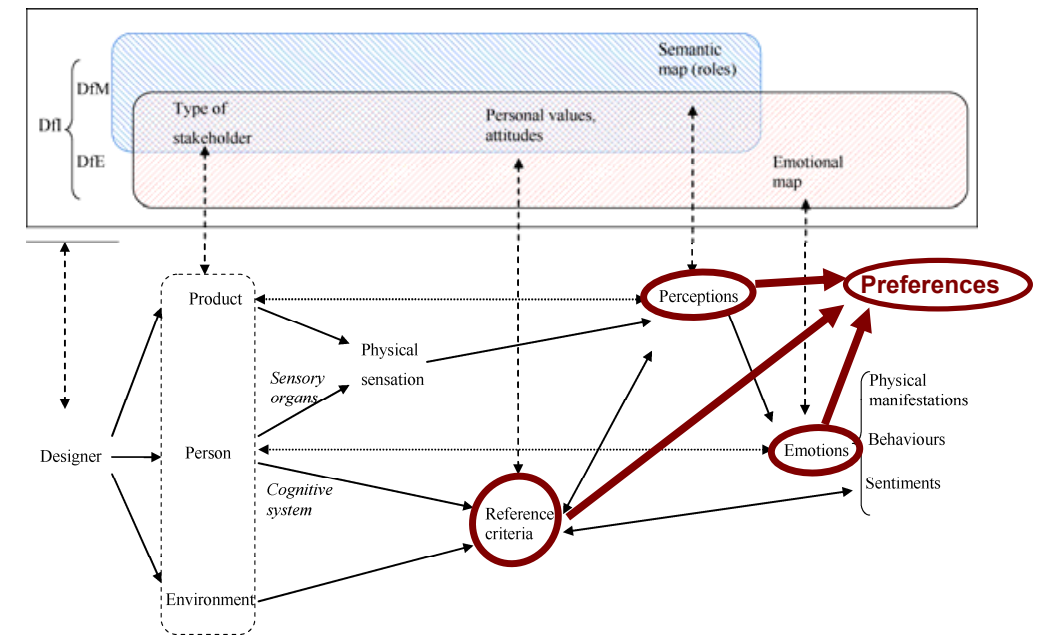

Fig. 1. Taking the customers' impression into the collaborative design

A number of interesting aspects were taken from relevant works [6,7,8]. Our proposal considers the design process as a key moment for the study of customers' impression. It also considers the existence of different types of people who decide or inspect the product design, such as the architects, interior designers, commercial dealers, final users, etc. who may generate similar impressions inside a particular group, depending on their environment or reference criteria. Particularly, the pilot study focuses on the analysis of the perceptions that are most relevant to the product and the relationship of these perceptions with customer preferences (marked in red at Fig. 1). The relationship between perceptions and reference criteria is also suggested. 


\section{Pilot study for validation}

The validation of the conceptual framework is carried out through a pilot study in which several representative groups of ceramic industry customers participate. Nineteen different ceramic tiles were selected and each participant is asked about 3 of them to avoid boredom (different set for each participant). They answer a Semantic Differential test [9] about the perceptions and emotions that the images trigger within them (Figure 2). A third questionnaire, based on Rokeach's list [10], is used to determine the personal values and criteria of the participants. Although the study is not finished, a large number of tests have been completed participated by 250 participants. Some preliminary results are obtained and presented here.

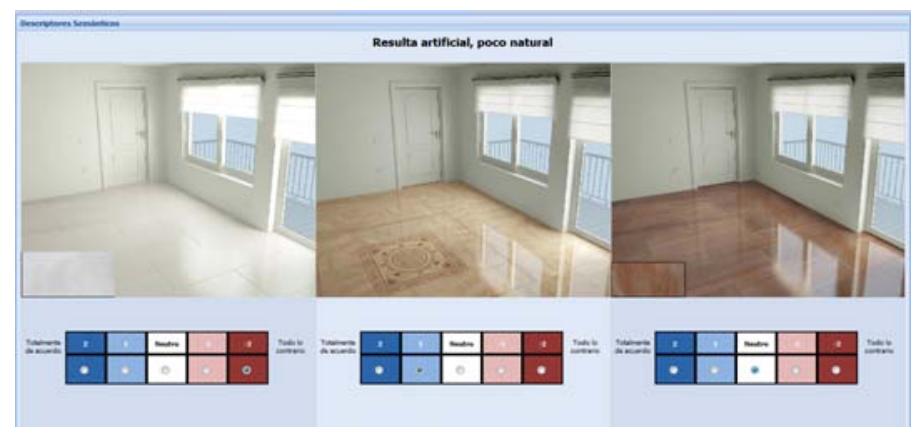

Fig. 2. Image of one of the impression tests with three ceramic products

From the 24 perceptions selected for the tests, 9 factors can be perceived for the ceramic tiles extracted with a factorial analysis, $80 \%$ of variance explained (see http://graficad.act.uji.es/tests/19 for the Spanish version of the test). Pearson correlations of these factors with the expressed preference (asked in a 0 to 10 scale, 10 for maximum preference) are shown in table 1. From this, it can be concluded that the most important perceptions for preference are the perception of "Functional, versatile, timeless", followed by "Stylish, innovative" and "Light, spacious". Other factors such as "Resistant", "Clean" and "Slippery" did not influence the preferences.

\begin{tabular}{|c|c|c|c|}
\hline & \multirow{2}{*}{$\begin{array}{l}\text { All data } \\
\mathrm{n}=642\end{array}$} & \multicolumn{2}{|c|}{ Modern, elegant people } \\
\hline Perception Factors & & Yes $(n=219)$ & No $(n=200)$ \\
\hline F1: Functional, versatile, timeless & $0,733 * *$ & & \\
\hline F2: Stylish, innovative & $0,352 * *$ & $0.542 * *$ & n.s. \\
\hline F3: Light, spacious & $0,259 * *$ & & \\
\hline F4: Resistant & n.s. & & \\
\hline F5: Clean & n.s. & & \\
\hline F6: Slippery & n.s. & & \\
\hline F7: Natural & $0,178^{* *}$ & n.s. & $0.290 * *$ \\
\hline F8: Domestic, homey & $0,134 * *$ & n.s. & $0.353 * *$ \\
\hline F9: Expensive & $0,111 * *$ & $0.200 * *$ & n.s. \\
\hline
\end{tabular}

Table 1. Pearson Correlations of perception factors with customers' preference. ${ }^{* *}$ Correlation significant at 0.01 level; *Correlation significant at 0.05 level; n.s.: non-significant correlation 
Table 1 also shows the correlations that change meaningfully by the personal value of 'Modern, elegant', as an example of the way that personal values may affect preference and perception. People that consider themselves as modern and elegant are influenced differently in their preference by the impression of "Stylish, innovative" and "Expensive".

\section{Conclusions and future work}

This work takes customer preferences into account in order to enrich a model of collaborative design for the ceramic industry. A conceptual framework was developed and a pilot study is being implemented to determine the relationship among product preferences, personal criteria, meanings and emotions for people who decide or verify the product design. Some relevant perceptions and their relations with personal criteria and preferences have been identified. Further analysis will help to identify more relations. Hence, the original model of collaborative design could be enriched with technical and managerial processes associated with the customers, who are the key stakeholder in the product development process.

Acknowledgments. We would like to thank the Fundació Caixa Castelló-Bancaixa and the Universitat Jaume I for the financial support of project Ref. P1-1B2008-21.

\section{References}

1. Camarinha-Matos, L. M., Afsarmanesh, H.: The Virtual Enterprise Concept. In: IFIP TC5 WG5.3 / PRODNET Working Conference on Infrastructures for Virtual Enterprises: Networking Industrial Enterprises, pp. 3 - 14, Vol. 153 (1999).

2. Romero, F., Company, P., Agost, M.J., Vila, C.: Activity modelling in a collaborative ceramic tile design chain: an enhanced IDEF0 approach. Res Eng Design 19, 1-20 (2008).

3. Agost, M.J., Romero, F., Vila, C., Company, P.: Use of Patterns for Knowledge Management in the Ceramic Tile Design Chain. Proceedings of the Third International Conference, CDVE 2006, pp. 65-74. Springer, Mallorca (2006).

4. Vila, C., Romero, F., Galmés, V., Agost, M.J.: Collaborative Solutions for Cooperation, Coordination and Knowledge Management in the Ceramic Tile Design Chain. In: Second International Conference, Proceedings of CDVE 2005 pp. 86-93. Springer, Mallorca (2005).

5. Agost, M.J., Vergara, M.: A Conceptual Framework for impressions elicited in humanproduct interaction. Design for Meaning and Design for Emotion. In: the Kansei Engineering and Emotion Research International Conference, pp. 1369-1377. Paris (2010).

6. Desmet, P. M. A., Hekkert, P.: Framework of product experience. Int. J. Design, 1(1), 57-66 (2007).

7. Fenech, O.C., Borg, J.C. Exploiting Emotions for Successful Product Design. In: 16th International Conference on Engineering Design, ICED '07. Paris (2007).

8. Crilly, N., Moultrie, J., Clarkson, P.J.: Seeing things: consumer response to the visual domain in product design. Design Studies, 25(6), pp. 547-577 (2004).

9. Osgood, Ch.E., Suci, G.J., Tannenbaum, P.H.: The Measurement of meaning, Illinois Press (1957).

10. Rokeach, M.: The Nature of Human Values. New York. The Free Press (1973). 